\title{
Quantitative analysis of the 1981 and 2001 Etna flank eruptions: a contribution for future hazard evaluation and mitigation
}

\author{
Maria A. Marsella ${ }^{1}$, Silvia Scifoni ${ }^{\star}{ }^{, 1}$, Mauro Coltelli $^{2}$, Cristina Proietti ${ }^{2}$ \\ ${ }^{1}$ Università di Roma "La Sapienza», Dipartimento di Ingegneria Civile, Edile e Ambientale (DICEA), Rome, Italy \\ ${ }^{2}$ Istituto Nazionale di Geofisica e Vulcanologia, Sezione di Catania, Osservatorio Etneo, Catania, Italy
}

Article history

Received November 22, 2010; accepted May 15, 2011.

Subject classification:

Volcanic risk, Volcano monitoring, Volcanic eruptions, Instruments and techniques, Measurements and monitoring.

\begin{abstract}
Lava flows produced during Etna flank eruptions represent severe hazards for the nearby inhabited areas, which can be protected by adopting prompt mitigation actions, such as the building of diversion barriers. Lava diversion measures were attempted recently during the 1983, 1991-93, 2001 and 2002 Etna eruptions, although with different degrees of success. In addition to the complexity of barrier construction (due to the adverse physical conditions), the time available to successfully slow the advance of a lava flow depends on the lava effusion rate, which is not easily measurable. One method to estimate the average lava effusion rate over a specified period of time is based on a volumetric approach; i.e. the measurement of the volume changes of the lava flow over that period. Here, this has been compared to an approach based on thermal image processing, as applied to estimate the average effusion rates of lava flows during the 1981 and 2001 Etna eruptions. The final volumes were measured by the comparison of pre-eruption and post-eruption photogrammetric digital elevation models and orthophotographs. Lava volume growth during these eruptions was estimated by locating the flow-front positions from analyses of scientific papers and newspapers reports, as well as from helicopter photographs. The analyses of these two eruptions contribute to the understanding of the different eruptive mechanisms, highlighting the role of the peak effusion rate, which represents a critical parameter for planning of mitigation actions and for hazard evaluation.
\end{abstract}

\section{Introduction}

Mount Etna is characterized by intense volcanic activity at the summit area, although this does not usually pose a danger to nearby inhabited areas. On the contrary, lava flows from flank eruptions can pose a severe threat to the nearby villages and towns located at lower altitudes. Most of the recent flank eruptions were characterized by low average lava effusion rates of relatively long durations; e.g. during the 1950-51,1983, 1984, 1985, 1991-93, 2001 and 2002-03 eruptions. However, in some cases, high average lava effusion rates of short duration, i.e. of days or weeks, have occurred, as in 1928, 1971 and 1981.
In terms of hazard mitigation, eruptions with low average lava effusion rates allow the setting up of civil protection measures during the flow emplacement; however, eruptions with high average effusion rates of short duration require proactive risk assessment and interventions. The 1981 and 2001 eruptive events of Etna are examples of both eruption patterns. Indeed, the lava flows from the $2,550 \mathrm{~m}$ and 2,700 $\mathrm{m}$ a.s.l. vents during the 2001 eruption were characterized by low effusion rates and a relatively slow lava advance, thus allowing the National Department of Civil Protection to build 13 earth barriers to protect the "Rifugio Sapienza" tourist facilities [Scifoni et al. 2010]. In contrast, the 1981 eruption, and in particular its main flow, was characterized by a very fast lava flow. If the 2001 effusion rate had reached a peak value as high as that of the 1981 eruption, it would have been not possible to set up similar mitigation measures.

Clearly, to assess the time available to implement successful mitigation measures, it is necessary to estimate the effusion rate trend. Unfortunately, direct and frequent measurements of this parameter are not easily achievable. During an eruption, instantaneous effusion rates can be estimated roughly in the field, or remotely using satellite thermal images. The time-averaged discharge rates (TADRs) can also be evaluated by applying topographic and photogrammetric techniques to extract digital elevation models (DEMs) during syn-eruption surveys. In this way, it is possible to measure the lava volume growth over a known time span, from which the TADR can be evaluated.

In the present study, a volumetric approach was applied to reconstruct the geometrical evolution of the lava fields, and for post-event estimation of the TADR trends of the lava flows during the 1981 and 2001 eruptions. This approach is based on comparisons of pre-eruption and post-eruption topographic surfaces, which are obtained by applying digital aerial photogrammetric techniques. In the absence of syneruption surveys, the temporal evolution of the lava flows is 


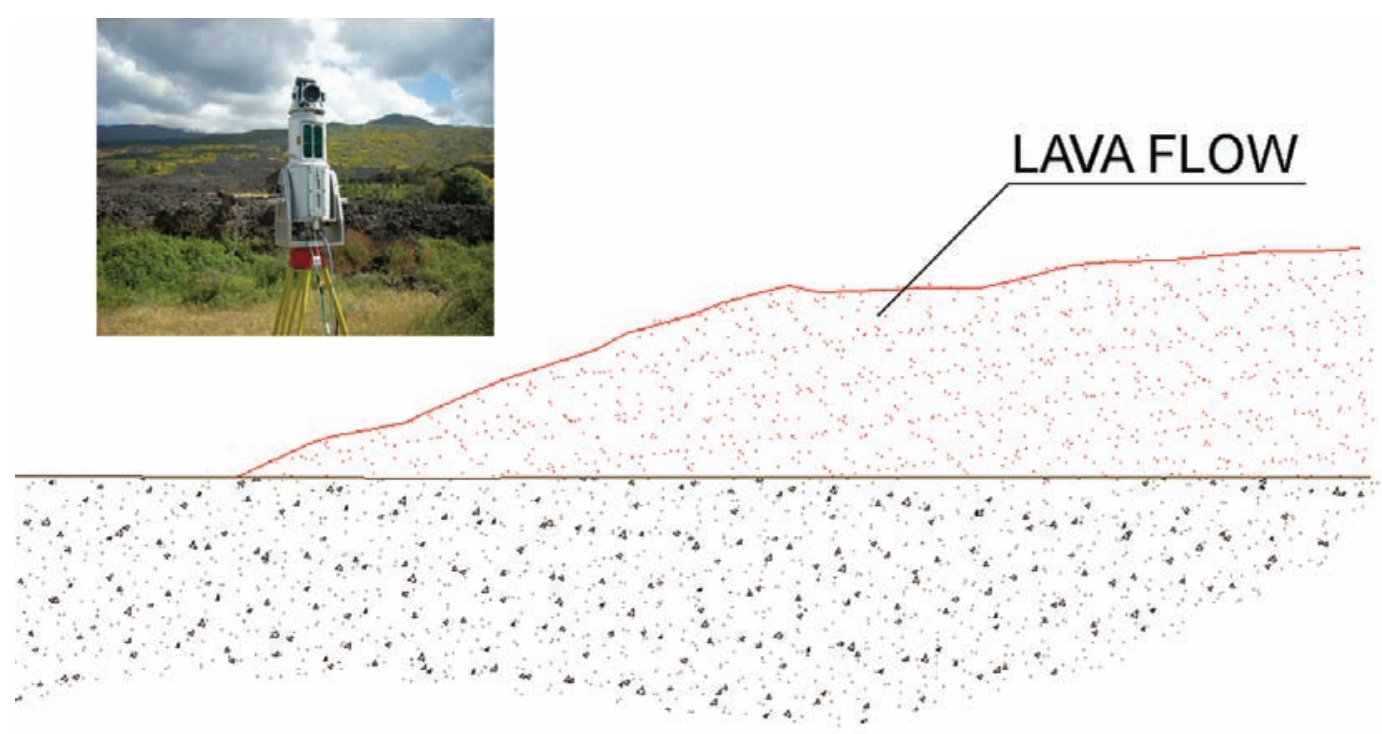

Figure 1. Laser scanner survey of the lava flow front of the 1981 Etna eruption. Red line, section cut along the 1981 lava front.

reconstructed using various data sources, such as scientific papers, newspaper reports and photographs taken during the eruptions.

\section{Syn-eruption surveying techniques for volumetric TADR estimation}

Different techniques that are based on ground, aerial and satellite sensors can be adopted for obtaining syneruption data, with the implementation of a volumetric approach for the estimation of the effusion rate trends. Remote sensing techniques that are based on aerial and satellite optical sensors have wider fields of view than ground sensors, and therefore they are the preferred approach to safely obtain useful data for the quantitative observation of a whole lava field. However, these techniques are usually characterized by poor georeferencing accuracy, and they are limited by cloud and plume coverage.

Previous studies have demonstrated that the comparison of pre-eruption and post-eruption DEMs, as extracted directly from photogrammetric surveys or interpolated from available contour maps, is effective for estimation of the final volumes of lava flows of past eruptions [Stevens et al. 1999, Coltelli et al. 2007, Marsella et al. 2008]. In addition, the possibility of repeating photogrammetric surveys during the active phase of an eruption allows reconstruction of the lava flow evolution throughout the whole eruption [Marsella et al. 2008, 2009]. When such data are not available or are insufficient, an analysis of helicopter photographs that are usually taken for monitoring purposes can be used to follow the enlargement of a lava flow field and to evaluate lava volume growth, by using approximate thickness values. To improve the measurement accuracy, the helicopter photographs should be orthorectified, to minimize the distortion caused by variable flight patterns and the use of non-calibrated lenses. Alternatively, low-altitude flying platforms, such as unmanned aerial vehicles or ultralight aeroplanes [Laliberte et al. 2008, Buckley et al. 2002], can be equipped with calibrated digital cameras and a global positioning system/inertial motion unit system for direct georeferencing, to acquire a large number of quasi-nadiral aerial photographs.

Ground-based topographical techniques with threedimension capability can be adopted, either by using digital cameras to acquire stereo-pairs, or laser scanner sensors to obtain three-dimensional points (Figure 1), which can in theory provide higher time/space resolution than remotesensing surveys. However, close-range surveys are not always feasible in areas that can be difficult to access [James et al. 2008]. Moreover, close-range surveys are useful for rapid evaluation of the advance of simple lava flows, but they are not appropriate to monitor complex lava flow fields, which require multiple points of observation. A close-range survey on an active lava flow was initially conducted during the 2008-2009 Etna eruption using a very-long-range terrestrial laser scanner [James et al. 2009]. These authors showed that this instrument allows changes due to the emplacement of new lava flows to be detected, even if data co-registration difficulties arise from very-long-range observations of extremely rough topographies. The datasets obtained were characterized by irregular distributions, and in some areas, by very low densities. The survey was possible since it was performed inside the Valle del Bove depression; as opposed to most of the Etna surface, the Valle del Bove depression offers many points of observation from which to measure a large area of a lava flow.

\section{Techniques for TADR estimation}

To quantify lava emplacement processes, and in particular the evolution of the TADR that gives a general view of an eruption, the DEMs produced during an eruption 
can be analyzed. Provided that pre-eruption DEMs are available, these data allow the implementation of a volumetric approach for estimation of the TADR, by dividing the volume of the lava flow by the corresponding time interval. Quality control analysis of volume estimates, which directly affect the TADRs, show margins of error of about 10\% [Coltelli et al. 2007].

Aerial laser scanning and digital photogrammetry are suitable for acquiring data over large areas, so these techniques are more appropriated to observe the evolution of lava flow fields. The surveying frequency depends on the availability of aerial platforms (helicopter or aircraft) close to an eruption site.

Volumetric TADRs provide a general view of an eruption and they can be adopted to constrain instantaneous evaluations of the lava effusion rate, which can be performed through different methodologies, such as field measurements and processing of thermal images, which are more suitable for detecting short-term variations. In the field-based approach, effusion rates are evaluated by in-situ measurements of lava velocity, and channel width and depth [Frazzetta and Romano 1984, Guest et al. 1987, Calvari et al. 1994, Calvari et al. 2002]. However, channel geometry is difficult to obtain, because the depth is not necessary the same as the levee height [Pinkerton and Sparks 1976], and the width is usually not constant along the flow depth [Guest at al. 1987]. The flow velocity is easy to measure at the flow center, but it varies for down-flow and cross-flow directions, as well as vertically within a channel. All of these uncertainties can result in cumulative errors in the effusion rates of as much as $37 \%$ [Calvari et al. 2002].

In the thermal approach, the effusion rate is derived from the radiance measured from both satellite-borne infrared sensors and hand-held thermal cameras, which obtain minimum and maximum values for the effusion rate, as a range of surface temperatures of the active lava flow is generally assumed for the calculations. Recent studies have demonstrated that satellite effusion rate measurements can have margins of error of up to 50\% [Harris et al. 2007]. Moreover, the values estimated from satellites are not limited to a single vent, but apply to the whole of a lava field. For this reason, in case of multi-vent eruptions, the volumes derived by integrating effusion rate thermal measurements are not always reliable and directly applicable when it is necessary to distinguish the contributions of the various lava flows. For example, minimum and maximum effusion rate trends were obtained for the whole 2001 Etna eruption from the analysis of thermal advanced very-high-resolution radiometer (AVHRR) data [Lautze et al. 2004], but the eruption included seven different lava flows, with only two of these threatening buildings (those from the $2,550 \mathrm{~m}$ and 2,700 $\mathrm{m}$ a.s.l. vents).

The 2001 Etna eruption can be used to compare total

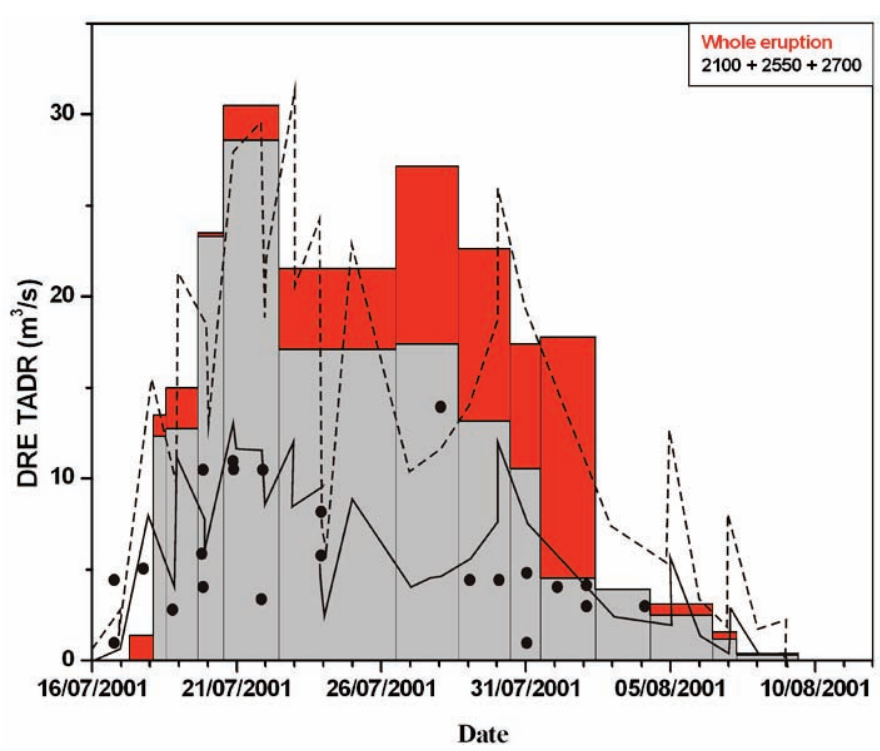

Figure 2. Comparison of the different lava effusion rate trends of the whole 2001 Etna eruption, based on: the volumetric approach (filled red bars); analysis of thermal images acquired by satellite (minimum and maximum values, continuous and dashed lines, respectively; redrawn from Lautze et al. [2004]); and ground measurements (dots, redrawn from Lautze et al. [2004]). The volumetric TADR was also evaluated considering only the lava flows from the 2,100 m, 2,550 $\mathrm{m}$ and 2,700 $\mathrm{m}$ a.s.l. vents (filled grey bars), where the final volume is $70 \%$ of the total volume.

volumes and effusion rates obtained both by thermal and volumetric approaches, and by field measurements. Lautze et al. [2004] analyzed thermal AVHRR data and ground-based data to evaluate dense-rock equivalent (DRE) effusion rates of the whole lava field throughout the eruption. The integral calculus of the DRE thermal effusion rates gave a final lava DRE volume of $19.8( \pm 7.7) \times 10^{6} \mathrm{~m}^{3}$. This value has little overlap with the DRE volume of $31.3( \pm 5.8) \times 10^{6} \mathrm{~m}^{3}$ obtained from the bulk volume evaluated by the volumetric approach [Coltelli et al. 2007], after the correction for vesicularity of $22 \%$ $( \pm 12 \%)$ [Harris et al. 2000]. It also differs from the DRE volume of $37.5( \pm 5.5) \times 10^{6} \mathrm{~m}^{3}$ evaluated by field measurements [The Research Group of the Istituto Nazionale di Geofisica e Vulcanologia-Sezione di Catania, Italy 2001]. This comparison confirms that the use of highly scattered effusion rates makes satellite data unsuitable for estimating volumes, due to the large differences with the volumes measured.

The volumetric approach was applied to reconstruct the trends of the TADRs corresponding to the Etna lava flows from the 2,100 $\mathrm{m}, 2,550 \mathrm{~m}$ and 2,700 $\mathrm{m}$ a.s.l. vents [Coltelli et al. 2007, Scifoni et al. 2010], which were mostly active during the central period of the eruption (July 23 to August 3), and produced about $70 \%$ of the final lava volume of the whole eruption. The volumetric DRE TADR trends (Figure 2) were compared with the corresponding evaluations for the entire eruption using ground-based data and satellite thermal images [Lautze et al. 2004]. The DRE TADR trends in Figure 2 are comparable. However, while the isolated peaks measured by ground and satellite data can be linked to 


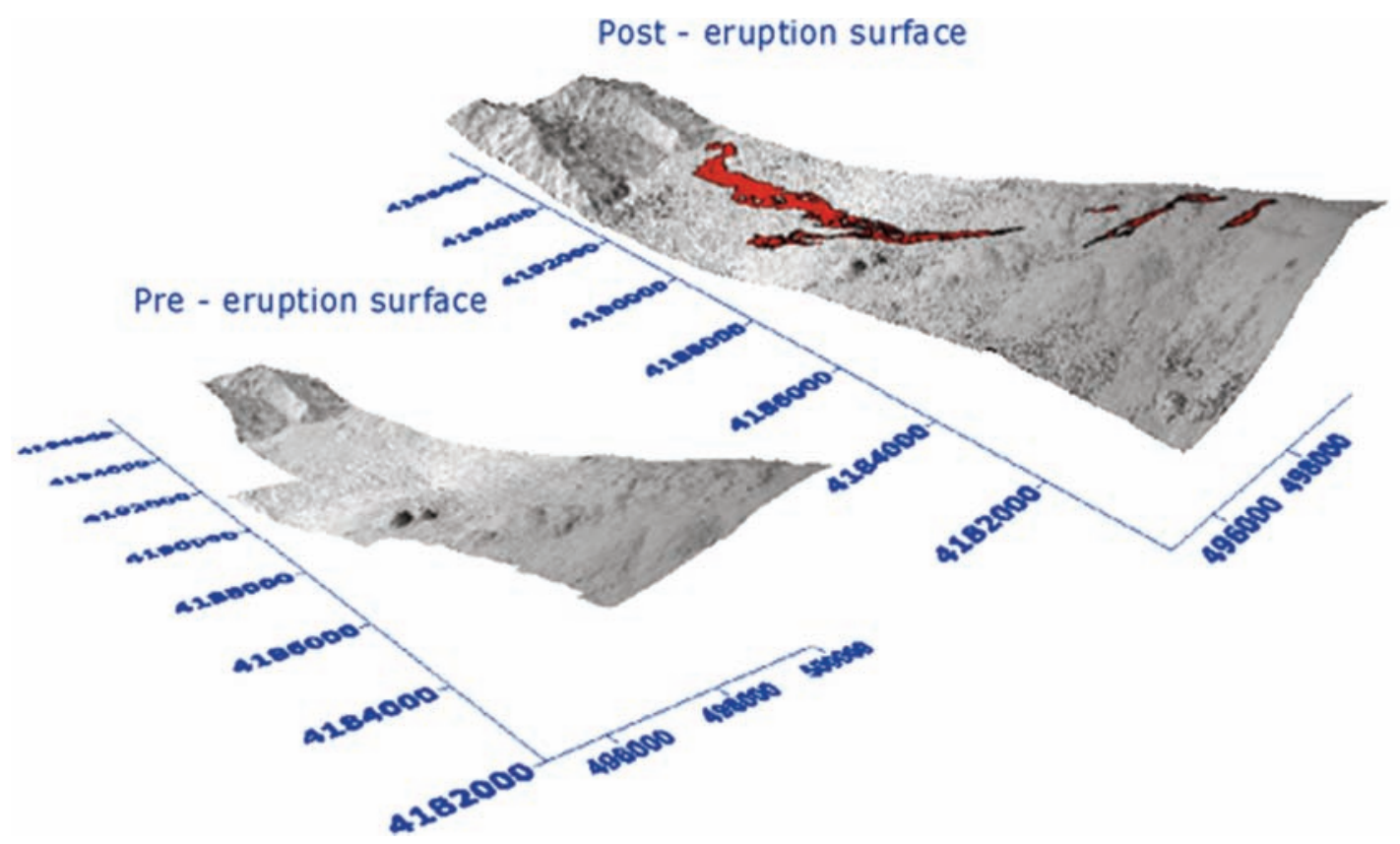

Figure 3. Pre-eruption (left) and post-eruption (right) surfaces of the 1981 Etna eruption, with the lava flow fields superimposed in red on the posteruption surface.

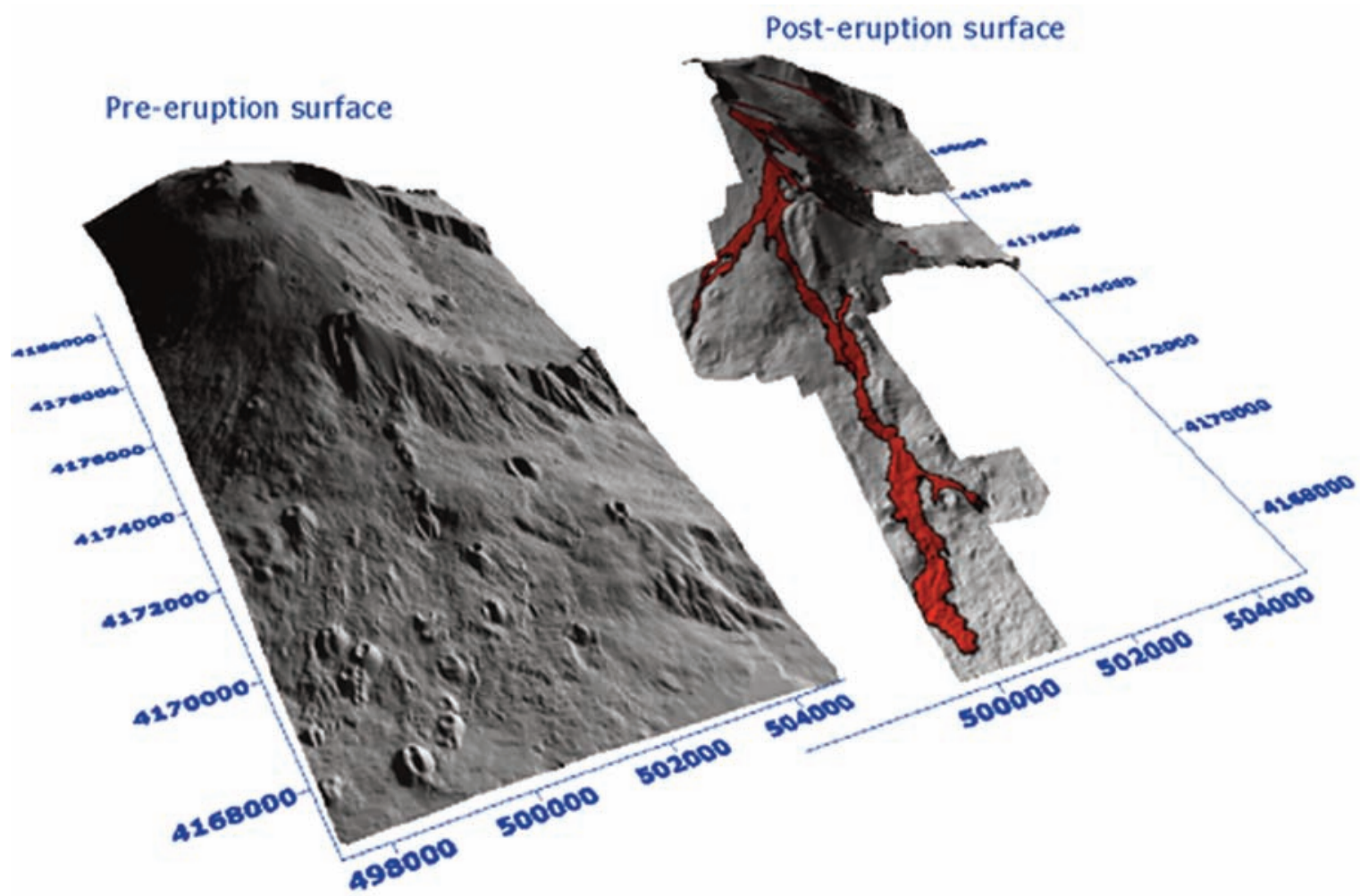

Figure 4. Pre-eruption (left) and post-eruption (right) surfaces of the 2001 Etna eruption, with the lava flow fields superimposed in red on the posteruption surface.

pauses or pulses in the effusive activity, these cannot be represented by the volumetric approach, which produces an average value corresponding to a time span ranging from one to several days. Furthermore, the peak visible for the satellite dataset in the decreasing phase (July 30 to August 1) might be due to the contribution of the lava flows from upper vents, which were not considered in the volumetric approach. The large differences between the upper and lower satellite effusion rates appear too wide, and thus they suggest that the assumptions in the model of the range of lava surface temperatures were not correct [Lautze et al. 2004].

Generally, thermally derived effusion rates are sensitive to short-term variations that are highlighted by spikes in the dataset. On the contrary, as the volumetric data is strongly 
dependent on the low acquisition frequency, this can provide average effusion rates that cannot depict rapid variations in lava discharge. More specifically, the volumetric approach cannot be used to represent short-term peaks, because of the timing of aerial surveys, as only one carried out every few days. The efficacy of the satellite approach in the detection of short-term peaks is also limited by bad weather and plume coverage.

\section{Analysis of the 1981 and 2001 Etna eruptions}

The reconstructions of the 1981 and 2001 TADRs were performed using a similar approach to that described by Coltelli et al. [2007]; i.e. they were based on comparative analyses of pre-eruption and post-eruption DEMs extracted from photogrammetric surveys and on post-eruption orthophotographs. These analyses allowed the precise definition of the limits of the lava flows, to evaluate their final volumes and to extrapolate their temporal evolution.

The 1981 pre-eruption DEM was extracted using photogrammetric data from a 1978 aerial survey (flight altitude, 3,000 m; scale, 1:20.000) that was carried out by "Rossi Brescia S.r.l.". These data were processed through a photogrammetric digital workstation. The post-eruption topography was extracted by processing photogrammetric data that was collected during a 2004 aerial survey (scale, $1: 10.000)$ that was performed by "Nuova Avioriprese Napoli". To cover the whole lava field (Figure 3), it was necessary to integrate this 2004 DEM with a DEM obtained by interpolation of a 1999 vector map (scale, 1:10.000) of the Provincia Regionale di Catania, which was extracted from an aerial survey that was performed on November 9, 1998 [Coltelli et al. 2007]. This 1999 DEM was also adopted as the 2001 pre-eruption surface, with the corresponding posteruption DEM (Figure 4) interpolated from the 2001 vector map of the Provincia Regionale di Catania, as extracted from a December 3, 2001, aerial survey [Coltelli et al. 2007].

For both of these eruptions, the pre-eruption and posteruption DEMs were compared, to evaluate the elevation changes, as represented by two residual maps. These maps allowed the distribution of the lava flow thicknesses for both of these eruptions to be evaluated (Figures 5 and 6). Global positioning system surveys were also carried out on the 1981 lava flows, to reconstruct the lava flow surface where preeruption vegetation or post-eruption land modifications prevented the precise measurement of lava thicknesses by the photogrammetric approach. For both of these eruptions, the post-eruption orthophotographs helped to localize the flowfront positions that were retrieved by the data analysis. The advance of the 1981 front was reconstructed by taking into account various data sources, such as the scientific literature, newspaper reports, and other documents. To obtain the partial volumes at different times, and the corresponding TADRs, the final lava thickness was cut in correspondence with the time evolution of the front position (Figure 7). The

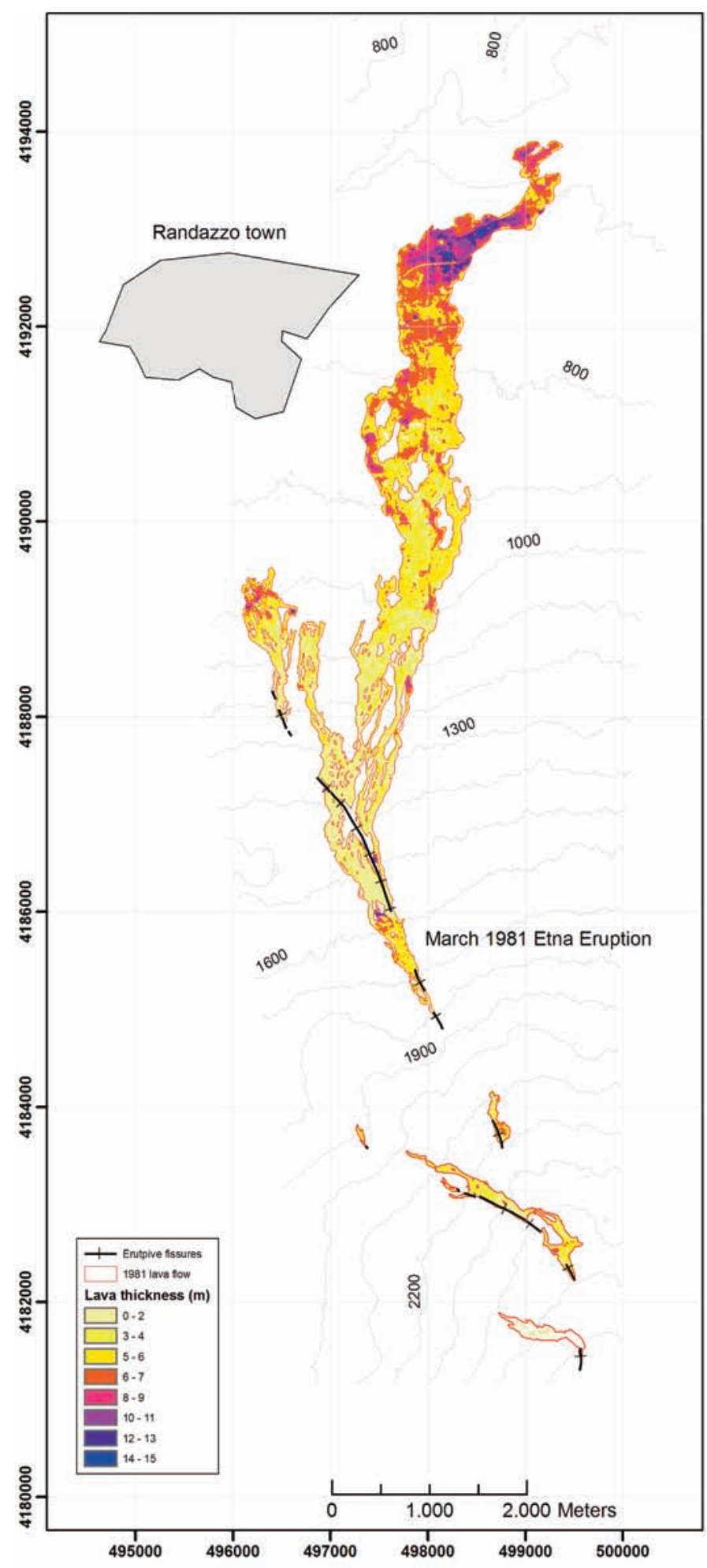

Figure 5. Lava flow thickness distribution and eruptive fissures of the 1981 Etna eruption.

front evolution of the 2001 lava flows (for the $2,550 \mathrm{~m}$ and $2,700 \mathrm{~m}$ a.s.l. vents) was reconstructed from the analysis of Istituto Nazionale di Geofisica e Vulcanologia (INGV) reports and helicopter photographs, which provided an almost daily mapping of the flow limits [Scifoni et al. 2010] (Figure 8).

The reconstruction of the advance of the flow fronts during both the 1981 and 2001 eruptions not only allowed 


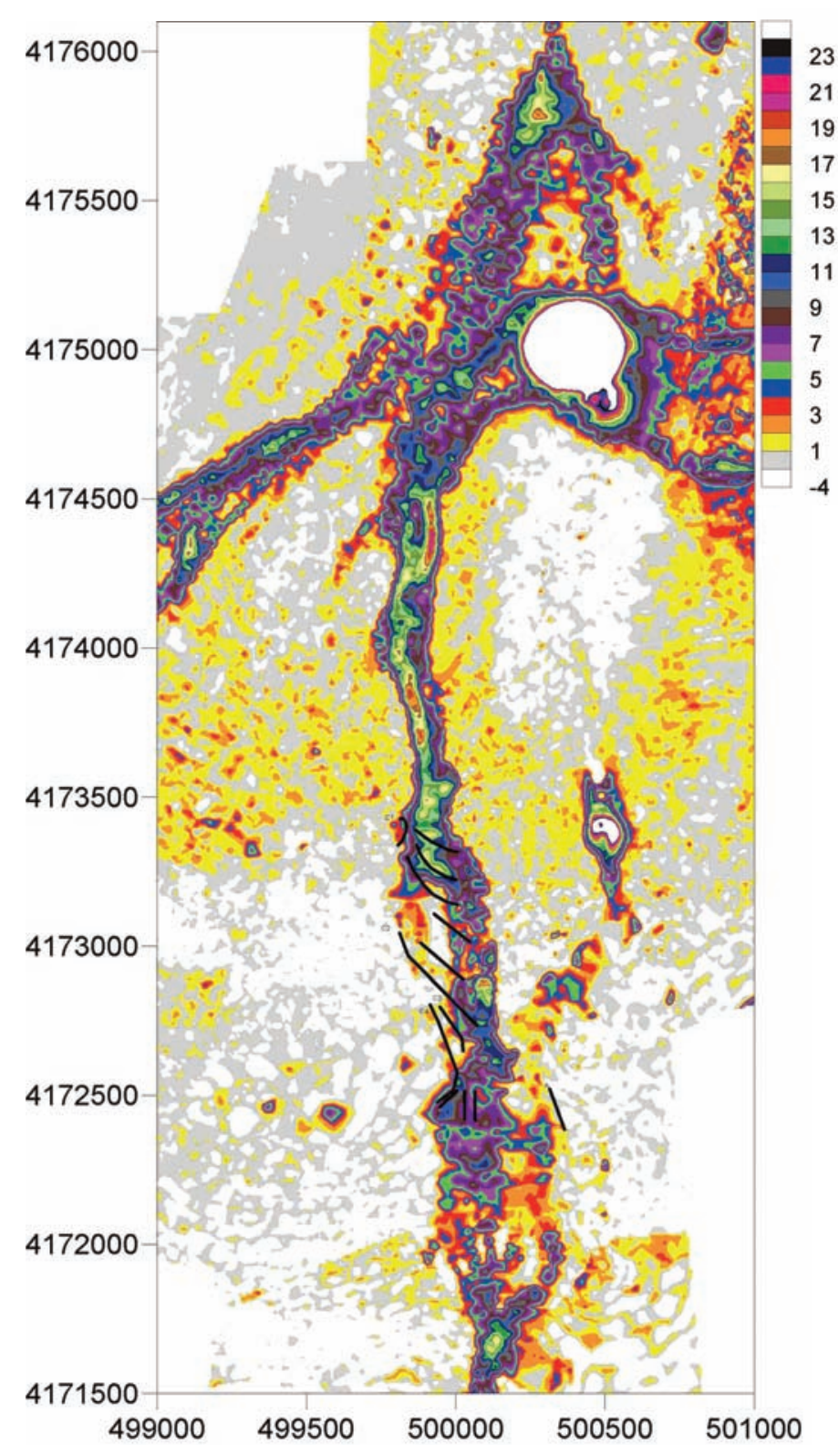

Figure 6. Lava flow thickness distribution of the 2001 Etna eruption from the $2,700 \mathrm{~m}$ and 2,550 $\mathrm{m}$ a.s.l. vents. Black lines, position of the 13 earth barriers built during the eruption.

evaluation of their TADRs, but also analysis of the evolution of the lava flows during each eruption. Indeed, the two slowly evolving 2001 lava flows (from the 2,550 $\mathrm{m}$ and 2,700 $\mathrm{m}$ a.s.1. vents) were complete in 6 days and 10 days [Scifoni et al. 2010] and reached lengths of $3.3 \mathrm{~km}$ and $4.1 \mathrm{~km}$, respectively [Coltelli et al. 2007]. This allowed the civil protection authorities to build earth barriers to protect the buildings at "Rifugio Sapienza" [Barberi et al. 2004]. Moreover, numerical simulations that used the reconstructed 2001 effusion rate trends demonstrated that it would also have been possible to develop alternative scenarios for the barrier configuration [Scifoni et al. 2010]. On the contrary, the 1981 effusion rate trend shows a quite different scenario: the main 1981 lava flow traveled $10 \mathrm{~km}$ in about 4 days, confirming that it would have been very

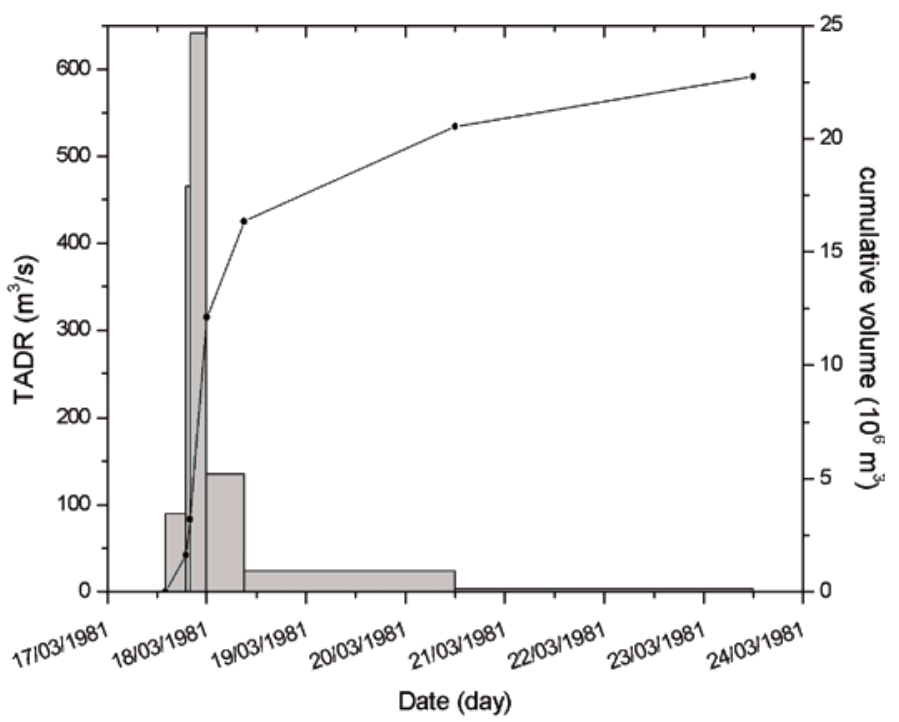

Figure 7. Temporal evolution of the TADR (left axis) and corresponding cumulative volumes (right axis) during the 1981 Etna eruption.

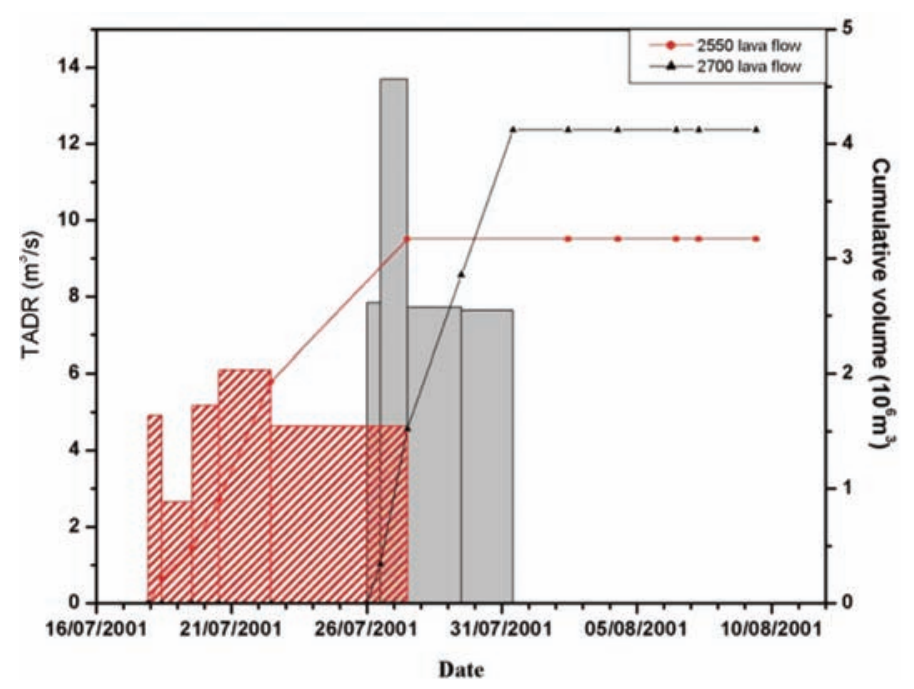

Figure 8. Temporal evolution of the TADR (left axis) and the corresponding cumulative volumes (right axis) during the 2001 Etna eruption. Gray bars and black triangles, lava flow from the 2,550 $\mathrm{m}$ a.s.l. vent. Red bars and red circles, lava flow from the $2,700 \mathrm{~m}$ a.s.l. vent. (from Scifoni et al. [2010]).

difficult to build earth barriers in the short time available.

\section{Conclusions}

The analysis of the emplacement history of the recent Etna eruptions in 1981 and 2001, where the lava flows threatened inhabited areas, can be used to anticipate future eruptions and to assist in the design and implementation of mitigation actions. For both of these eruptions, a quantitative multi-temporal analysis of the lava flow evolution was developed to reconstruct their emplacement histories and evaluate the corresponding effusion rate trends. The results of the analysis were used to simulate (on the pre-eruption DEMs) the evolution of these 1981 and 2001 Etna eruptions, and to forecast different scenarios. 
The analysis of past events and the availability of reliable and rapid methods for syn-eruption measurements of effusion rates can be used to confirm numerical simulation results and to forecast lava flow paths of future eruptions, as well as to follow the evolution of on-going eruptions. Furthermore, quantitative analysis and reconstruction of past eruptions represent a starting point for the investigation and characterization of the different discharge mechanisms for Etna flank eruptions, which constitute the most hazardous events for the nearby inhabited areas.

\section{References}

Barberi, F. and M.L. Carapezza (2004). The control of lava flows at Mt. Etna, In: Mount Etna Volcano Laboratory, edited by A. Bonaccorso, S. Calvari, M. Coltelli, C. Del Negro and S. Falsaperla, Geophysical Monograph Series, 143, AGU, Washington, D.C., 357-369.

Buckley, S.J., J.P. Mills, P.J. Clarke, S.J. Edwards, J.S. Pethick and H.L. Mitchell (2002). Synergy of GPS, digital photogrammetry and INSAR in coastal environments, Proceeding of 7 th International Conference on Remote Sensing for Marine and Coastal Environments (Miami, Florida, May 20-22, 2002).

Calvari, S., M. Coltelli, M. Neri, M. Pompilio and V. Scrivano (1994). The 1991-1993 Etna eruption: chronology and lava flow-field evolution, Acta Vulcanologica, 4, 1-14.

Calvari, S., M. Neri and H. Pinkerton (2002). Effusion rate estimations during the 1999 summit eruption on Mount Etna, and growth of two distinct lava flow fields, J. Volcanol. Geoth. Res., 119, 107-123.

Coltelli, M., C. Proietti, S. Branca, M. Marsella, D. Andronico and L. Lodato (2007). Analysis of the 2001 lava flow eruption of Mt. Etna from three-dimensional mapping, J. Geophys. Res., Solid Earth, 112; doi: 10.1029/2006JF000598.

Frazzetta, G. and R. Romano (1984). The 1983 Etna eruption: event chronology and morphological evolution of the lava flow, B. Volcanol., 47, 1079-1096.

Guest, J.E., C.R. J. Kilburn, H. Pinkerton and A.M. Duncan (1987). The evolution of lava flow field: observation of 1981 and 1983 eruptions of Mount Etna, Sicily, B. Volcanol., 49, 527-540.

Harris A.J.L., J.B. Murray, S.E. Aries, M.A. Davies, L.P. Flynn, M.J. Wooster, R. Wright and D.A. Rothery (2000). Effusion rate trends at Etna and Krafla and their implications for eruptive mechanisms, J. Volcanol. Geoth. Res., 102, 237-270.

Harris, A.J.L., J. Dehn and S. Calvari (2007). Lava effusion rate definition and measurement: a review, B. Volcanol., 70, 1-22.

James, M.R., H. Pinkerton and S. Robson (2008). Imagebased measurement of flux variation in distal regions of active lava flows, Geochem. Geophys. Geosyst., 8, 3, Q03006; doi: 10.1029/2006GC001448.
James, M.R., H. Pinkerton and L.J. Applegarth (2009). Detecting the development of active lava flow fields with a very-long-range terrestrial laser scanner and thermal imagery, Geophys. Res. Lett., 36, L22305; doi: 10.1029/2009 GL040701.

Laliberte, A.S., C. Winters and A. Rango (2008). Procedure for orthorectification of sub-decimeter resolution imagery obtained with an unmanned aerial vehicle (UAV), Proceedings of the ASPRS 2008 Annual Conference (Portland, OR, April 28 - May 2, 2008).

Lautze, N.C., A.J.L. Harris, J.E. Bailey, M. Ripepe, S. Calvari, J. Dehn., S.K. Rowland and K. Evans-Jones (2004). Pulsed lava effusion at Mount Etna during 2001, J. Volcanol. Geoth. Res., 137: 231-246.

Marsella, M., M. Coltelli, C. Proietti, S. Branca and R. Monticelli (2008). 2002-2003 lava flow eruption of Stromboli: a contribution to understanding lava discharge mechanism using periodic digital photogrammetry surveys, In: The Stromboli Volcano: An Integrated Study of the 20022003 Eruption, edited by S. Calvari, S. Inguaggiato, G. Puglisi, M. Ripepe and M. Rosi, Geophysical Monograph Series, 182, AGU, Washington D.C., 229-246.

Marsella, M., C. Proietti, A. Sonnessa, M. Coltelli, P. Tommasi and E. Bernardo (2009). The evolution of the Sciara del Fuoco subaerial slope during the 2007 Stromboli eruption: Relation between deformation processes and effusive activity, J. Volcanol. Geoth. Res., 182, 201-213.

Pinkerton, H. and R.S.J. Sparks (1976). The sub-terminal lavas, Mount Etna: a case history of the formation of compound lava field, J. Volcanol. Geoth. Res., 1, 167-182.

Scifoni, S., M. Coltelli, M. Marsella, C. Proietti, Q. Napoleoni, A. Vicari and C. Del Negro (2010). Mitigation of lava flow invasion hazard through optimized barrier configuration aided by numerical simulation: The case of the 2001 Etna eruption, J. Volcanol. Geoth. Res., 192, 16-26.

Stevens, N.F., G. Wadge and J.B. Murray (1999). Lava flow volume and morphology from digitized contour maps: a case study at Mount Etna, Sicily, Geomorphology, 28, 251-261.

The Research Group of the Istituto Nazionale di Geofisica e Vulcanologia-Sezione di Catania, Italy (2001). Multidisciplinary approach yields insight into Mt. Etna eruption, Eos Trans. AGU, 82 (52), 653-656; doi: 10.1029/01EO00376.

\footnotetext{
${ }^{\star}$ Corresponding author: Silvia Scifoni, Università di Roma «La Sapienza», Dipartimento di Ingegneria Civile, Edile e Ambientale (DICEA), Rome, Italy; email: silvia.scifoni@uniroma1.it.

(C) 2011 by the Istituto Nazionale di Geofisica e Vulcanologia. All rights reserved.
} 